\title{
Effects of Azadirachtin on the Biology of Lutzomyia longipalpis (Diptera: Psychodidae: Phlebotominae) Adult Female, the Main Vector of American Visceral Leishmaniasis
}

\author{
CLÁUDIA ALVES DE ANDRADE-COELHO,${ }^{1,2}$ NATALY ARAUJO DE SOUZA, ${ }^{1}$ \\ VANDERLEI CAMPOS SILVA, ${ }^{1}$ ADELSON A. SOUZA ${ }^{3}$ MARCELO SALABERT GONZALEZ,${ }^{4}$ \\ AND ELIZABETH FERREIRA RANGEL ${ }^{1}$
}

J. Med. Entomol. 51 (4): 891-895 (2014); DOI: http://dx.doi.org/10.1603/ME12233

\begin{abstract}
The effects of azadirachtin A added to the sucrose diet of the adult females on the mortality, oviposition, and hatching of the sand fly vector of American visceral leishmaniasis Lutzomyia longipalpis (Lutz \& Neiva, 1912) were investigated. Concentrations of $0.1,1.0$, and $10.0 \mu \mathrm{g} / \mathrm{mg}$ of azadirachtin significantly increased insect mortality in comparison with control insects. The same dose also significantly reduced oviposition but not hatching. After a long development period, significantly fewer adult insects were obtained from eggs hatching by azadirachtin-treated females in a doseresponse manner. These results indicate that azadirachtin is a potent sterilizer that could be used against the development of $\mathrm{Lu}$. longipalpis populations and as a tool for studying physiological and biochemical processes in phlebotomine species.
\end{abstract}

KEY WORDS Lutzomyia longipalpis, azadirachtin, vector control

Lutzomyia longipalpis (Lutz \& Neiva, 1912) is the main vector of American visceral leishmaniasis (AVL; Lainson and Rangel 2003) in large areas of Latin America including Brazil, with $\approx 200$ million people in risk areas (Alves 2009, WHO 2013). In this scenario, integrated programs focusing on alternative methods to reduce the vector population in affected areas are essential to control parasite transmission (Guerin et al. 2002).

The triterpenoid azadirachtin A, isolated from seeds of the neem tree (Azadirachta indica A. Jussieu, Meliaceae), is known as a compound with antifeedant properties and neuroendocrine blockage action, leading to high mortality and interrupting the growth of insects and nematodes. It is considered efficient in controlling agricultural pests, with no apparent toxicity to vertebrates. Research has been intensified to explore the insecticidal potential of neem derivates in the control of arthropods and insects of medical and veterinary importance. The effects of azadirachtin on insect development are related to reducing hemolymphatic levels of ecdysteroids, which are directly in-

\footnotetext{
${ }^{1}$ Laboratório de Transmissores de Leishmanioses, Fundação Oswaldo Cruz, Av. Brasil, 4365, Manguinhos, Rio de Janeiro, RJ 21045900, Brasil.

${ }^{2}$ Corresponding author, e-mail: rabbit@ioc.fiocruz.br.

${ }^{3}$ Laboratório de Leishmanioses, Instituto Evandro Chagas, Levilândia, Rodovia Br 316, Km 07 S/ Nº, Ananindeuá, Belém, Pará 67030-000, Brasil.

${ }^{4}$ Departamento de Biologia Geral, Universidade Federal Fluminense, Morro do Valonguinho S/ ${ }^{\circ}$, Niterói, RJ, 24001-970, Brasil.
}

volved in development and reproduction (Rembold 1989).

Some recent investigations have focused on the impact of azadirachtin on the sand fly vectors of leishmaniases. Azadirachtin added to larval food of $L u$. longipalpis s.l. (Marcondes 2007), the vector for Leishmania (Leishmania) chagasi (Cunha and Chagas 1937) in the Americas (Lainson and Rangel 2003), blocks their metamorphosis in the second instar in addition to causing a considerable dose-dependent mortality rate (Andrade-Coelho et al. 2006). Studies showed that A. indica and Melia azedarach $\mathrm{L}$. fruit and leaves in natura significantly increased larval mortality in comparison to untreated insects, when offered as food. A. indica fruit and leaves blocked the molting of insects, which remained as third-instar larvae until the end of the experiment. M. azedarach fruit also blocked the molting of larvae, which remained permanently in the fourth instar (Andrade-Coelho et al. 2009).

The current study has focused on the long-term effects of azadirachtin on the reproduction of $L u$. longipalpis and whether azadirachtin may be used against the development of phlebotomine populations.

\section{Materials and Methods}

Insects and Feeding Procedure. Lu. longipalpis collected in the Municipality of Barcarena, City of Belém, State of Pará, Brazil, were maintained in the Leishmaniases Laboratory, Evandro Chagas Institute, at $25 \pm 1^{\circ} \mathrm{C}$ and $86 \pm 10 \%$ relative humidity as described 
by Ward (1977). Experimental groups were composed of three batches of 30 females and 30 males each. The females and males in cages (Barraud 1929) were fed with sugar food (standard diet) prepared using a mix of commercial sugar (Companhia União de Refinadores-Cosan, São Paulo, Brasil) plus mineral water (Minalba S. A. Fonte Água Santa, Campos do Jordão, São Paulo, Brasil) to reach a consistence of syrup ( $80 \%$ of commercial sugar with $20 \%$ of mineral water). Sugar diet with or without azadirachtin A was offered to adult females only in pieces of cotton drops of sugar meal on top of cages (to prevent sand flies from getting stuck in sugar solution) during day 1 . In $2 \mathrm{~d}$ following the adults return to take up the only sugar solutions without azadirachtin A. After this period, a hamster (Ethics Committee on Animal Use, protocol number 21/09-2) was anesthetized with ketamine by intraperitoneal inoculation of $0.25 \mathrm{ml}$, and exposed to the females for $2 \mathrm{~h}$. Individual blood-fed females were then transferred to polyethylene plastic tubes with plaster of Paris as a substrate, measuring $2.5 \mathrm{~cm}$ in diameter and $3.5 \mathrm{~cm}$ in height. The daily observations allowed us to monitor the oviposition process (females that laid eggs or not) until $10 \mathrm{~d}$ after blood feeding. The eggs of each female were counted and isolated in petri dishes with plaster of Paris as a substrate to allow observation of fertility rate (i.e., eggs that hatched and released first-instar stage larvae). In addition, following the methodology of Rangel et al. (1985), the development of larvae obtained in the different experimental groups was monitored until adult emergence to evaluate the long-term effects of azadirachtin on the population of Lu. longipalpis.

Azadirachtin Administration. Azadirachtin A (Sigma, St. Louis, MO) at a concentration of $1 \mathrm{mg} / \mathrm{ml}$ in ethanol: saline $(1: 4 ; 0.15 \mathrm{M} \mathrm{NaCl})$ was added to the standard diet to give final concentrations of $0.01,0.1$, 1.0 , and $10.0 \mu \mathrm{g}$ of azadirachtin per milliliter of sugar diet. Control group I was formed by nontreated adults that received only the standard sugar diet, and control group II consisted of adults that were fed on standard diet with ethanol: saline only.

Biological Evaluation. The biological effects of azadirachtin treatments on $L u$. longipalpis females were recorded by observation of mortality, oviposition, hatching of eggs, and long- term effects on the development of adults. Experimental groups were observed every day during the experiments. Each experiment was repeated at least three times.

Data Analysis. Significance of the results was analyzed using analysis of variance and Tukey's test (Armitage and Berry 1994) using StatsDirect Statistical Software (StatsDirect Ltd, Cheshire, United Kingdom) version 2.2.7 for Windows 98. Differences between treated and control insects were considered statistically significant when $P<0.05$. We also used the chi-square test of independence, $95 \% \mathrm{CI}$, and odds ratio (OR) implemented in the BioEstat 4.0 software (Ayres et al. 2005). Differences between treated and control groups were considered statistically significant when OR and $95 \% \mathrm{CI}$ were $>1.0$. Probability levels are

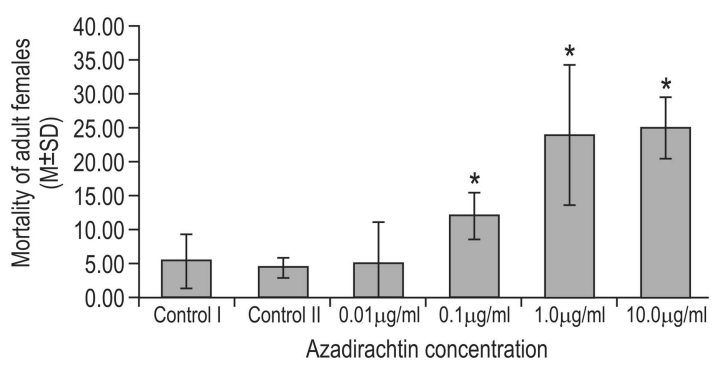

Fig. 1. Effect of azadirachtin A on the mortality of $L u$. longipalpis adult females. Nontreated insects (control I) were fed on standard diet. Insects in control II were fed on standard diet containing ethanol: saline (1:4). Azadirachtintreated females fed on standard diet containing different dose of azadirachtin A per milliliter: 0.01, 0.1, 1.0, and $10 \mu \mathrm{g}$, respectively. All treatments after standard diet were fed with hamster. Each group represents means and SD of at least three experiments. * indicates significant results

specified in the text. All experiments were repeated at least three times.

\section{Results}

Azadirachtin Effects on Mortality. As shown in Fig. 1 in the control groups I and II, only $5.5 \pm 4.9$ and $4.3 \pm$ $1.5(P<0.05)$ adult females died, respectively, at the end of the period of observation. The concentration of $0.01 \mu \mathrm{g}$ of azadirachtin per milliliter showed the same mortality level $(5 \pm 6.2)$ observed in control groups I and II $(P<0.05)$. The concentration of $0.1 \mu \mathrm{g}$ of azadirachtin per milliliter significantly increased the mortality to $12 \pm 3.4(P<0.01)$. However, the most significant mortality was seen in the groups treated with azadirachtin at concentrations of either 1.0 $\mu \mathrm{g} / \mathrm{ml}$ or $10 \mu \mathrm{g} / \mathrm{ml}$, which increased the mortality to $24 \pm 10.3$ and $25 \pm 4.5(P<0.0001)$ adult females in the same period, respectively.

Azadirachtin Effects on Oviposition. In the control groups I and II, $82.2 \pm 13.4$ and $85.5 \pm 5.0 \%$ of females performed oviposition during the observation period (Fig. 2A). In the control groups I and II, $3.3 \pm 0.3$ and $39.7 \pm 2.7(P<0.05)$ eggs were laid by each female during the experimental period, respectively (Fig. 2B). No significant difference was observed among control groups and the batches treated with 0.01 $\mu \mathrm{g} / \mathrm{ml}$ of azadirachtin, in which $83.3 \pm 20.8$ females laid eggs (Fig. 2A) with $40.3 \pm 2.8$ eggs deposited by each insect (Fig. 2B). However, in the group treated with $0.1 \mu \mathrm{g} / \mathrm{ml}$ of azadirachtin only $59.9 \pm 11.5$ females $(P<0.01)$ laid eggs during the experiment (Fig. 2A). Only $32.3 \pm 1.4$ eggs $(P<0.01)$ were laid by each female in this group (Fig. 2B). More significant decreases in oviposition were obtained when females were treated with 1.0 or or $10 \mu \mathrm{g} / \mathrm{ml}$ of azadirachtin, in which only $20 \pm 34.6 \%(P<0.0001)$ and $16.6 \pm$ $15.2 \%(P<0.0001)$ of females laid eggs, respectively (Fig. 2A). Similarly, only $8.5 \pm 1.4(P<0.0001)$ and $13.8 \pm 1.5(P<0.001)$ eggs were deposited by each insect in the groups treated with 1.0 and $10 \mu \mathrm{g} / \mathrm{ml}$ of azadirachtin, respectively. 

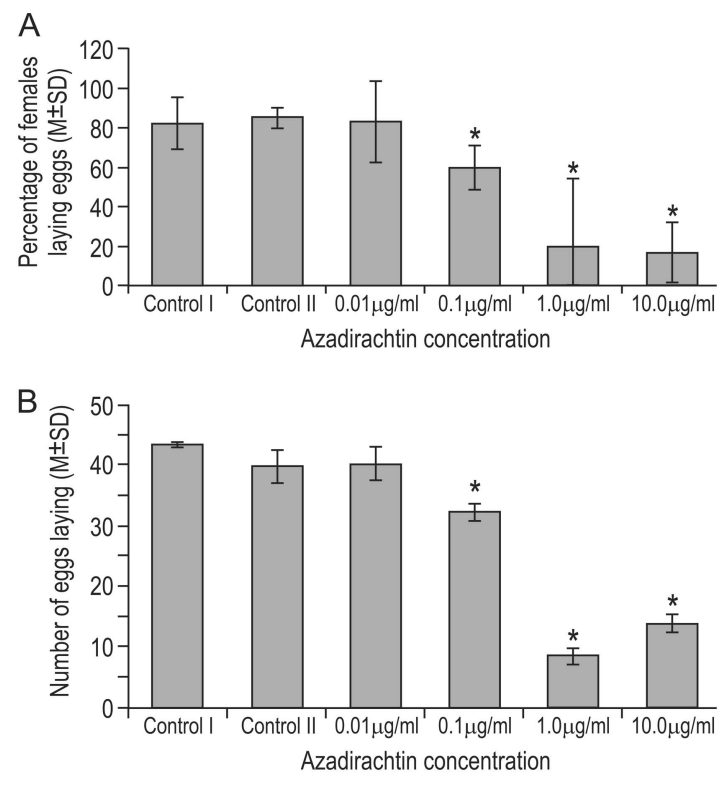

Fig. 2. Percentage of Lu. longipalpis females laying eggs (A) and the number of eggs laid (B) after azadirachtin A treatment. Nontreated insects (control I) were fed on standard diet. Insects in the control group II were fed a standard diet containing ethanol: saline (1:4). Azadirachtin-treated females fed on standard diet containing different dose of azadirachtin A per milliliter: 0.01, 0.1, 1.0, and $10 \mu \mathrm{g}$, respectively. All treatments after standard diet were fed on a hamster. Each group represents means and SD (percentage) of at least three experiments. * indicates significant results.

Azadirachtin Effects on the Eclosion of Eggs. There was no effect of the different doses of azadirachtin on the eclosion of eggs in Lu. Longipalpis (Table 1).

Long-term Effects of Azadirachtin on Lu. longipalpis Population. Table 1 shows the pooled results for all insects tested from each experimental group (treated or not treated with azadirachtin) and show the total number and percentage of adults emerged and number of eggs laid and hatched from these adults. A strong dose-response reduction in the total number of adult insects derived from females treated with azadirachtin was observed. About 1,000 adult insects developed from eggs deposited by females in the con- trol groups I and II, whereas 86 and $90 \%$ fewer adults were obtained from eggs laid by females in the groups treated with 1.0 and $10.0 \mu \mathrm{g} / \mathrm{ml}$ of azadirachtin, respectively. Throughout the experiments, significant differences were observed in the total number of eggs laid and hatched and also in the total number and percentages of adult derived from females from the control groups and groups treated with $0.1(\mathrm{OR}=0.9$ and $95 \% \mathrm{CI}=0.8-1.0), 1.0(\mathrm{OR}=1.1$ and $95 \% \mathrm{CI}=$ $0.9-1.3)$, and $10.0(\mathrm{OR}=1.1$ and $95 \% \mathrm{CI}=0.8-1.3)$ $\mu \mathrm{g} / \mathrm{ml}$ of azadirachtin.

\section{Discussion}

Azadirachtin has proven to be an effective sterilizer in adult insects. After ingesting the compound, females from various orders of insects are sterilized because of the inhibition of hormones involved in regulation of vitellogenin synthesis or ovarian maturation (Rembold 1984, Koul et al. 1990).

The effects of azadirachtin on the development and reproduction of various insect species may be related to its interference in the levels of hemolymph ecdysteroids (Redfern et al. 1981, Garcia et al. 1990) and juvenile hormone (Rembold and Sieber 1981, Rembold 1987). This interference would be a consequence of the compound's inhibition of the release of both neurosecretory material (Subrahmanyam and Rembold 1989) and prothoracicotropic hormone (Garcia et al. 1990).

In Rhodnius prolixus Stål, vitellogenesis is dependent on juvenile hormone, and when this hormone is applied topically it reverses the inhibitory effect of azadirachtin on reproduction, as only $45 \%$ of the eggs laid by females treated with $5 \mu \mathrm{g}$ of azadirachtin per milliliter of blood achieved hatching (Feder et al. 1988).

Our data demonstrated that in the control groups I and II as well as in the treatment of females with azadirachtin at a concentration of $0.01 \mu \mathrm{g} / \mathrm{mg}$, there was an increase in the mortality of females for $10 \mathrm{~d}$, reaching $16.7 \%$. Although this percentage could be considered high, these results are in agreement with the early observations of Rangel et al. (1985), who showed a low rate of survival of $L u$. longipalpis reared in the laboratory under standard sugar diet conditions.

Table 1. Long-term effects of azadirachtin $\mathrm{A}$ on the population of Lu. longipalpis adults developed from eggs deposited by treated females

\begin{tabular}{lccc}
\hline $\begin{array}{l}\text { Azadirachtin concn } \\
(\mu \mathrm{g} / \mathrm{ml})\end{array}$ & $\begin{array}{c}\text { Total no. of } \\
\text { eggs laid }\end{array}$ & Total no. of hatched eggs $(\%)$ & Total no. of adults emerged $(\%)$ \\
\hline Control I & 3,234 & $2,190(67.72)$ & $1,002(45.75)$ \\
Control II & 2,926 & $2,200(75.19)$ & $1,000(45.45)$ \\
0.01 & 3,075 & $2,000(65.04)$ & $880(44.00)$ \\
$0.1^{a}$ & 1,720 & $1,200(69.77)$ & $720(60.00)$ \\
$1.0^{b}$ & 459 & $300(65.36)$ & $140(46.67)$ \\
$10.0^{c}$ & 428 & $280(65.42)$ & $100(35.71)$ \\
\hline
\end{tabular}

The development of first- instar larvae obtained in the different experimental groups was monitored until adult emergence.

${ }^{a} \mathrm{OR}=0.9 ; 95 \% \mathrm{CI}=0.8-1.0$

${ }^{b} \mathrm{OR}=1.1 ; 95 \% \mathrm{CI}=0.9-1.3$.

${ }^{c} \mathrm{OR}=1.1 ; 95 \% \mathrm{CI}=0.8-1.3$ 
In the current study, we also observed partial sterilizing effects in adult specimens of Lu. longipalpis treated with azadirachtin, as oviposition was strongly inhibited by treatment. However, the eggs laid by females treated with azadirachtin hatched and succeeded in reaching the adult phase. The juvenile hormone levels in Lu. longipalpis remained low during vitellogenesis and probably increased only after the bloodmeal, as shown by Mahmood et al. (1992) in Lu. anthophora. Thus, additional experiments using ecdysone therapy and juvenile hormone treatment are necessary to clarify how azadirachtin disrupts the oviposition process in Lu. longipalpis.

The data for Lu. longipalpis show the impact of azadirachtin at doses of $0.1,1.0$, and $10.0 \mu \mathrm{g} / \mathrm{ml}$ causing both mortality and reducing the number of eggs laid per treated female. Despite the observation that azadirachtin did not affect the hatching of eggs deposited by treated females, the cumulative effects of mortality and oviposition inhibition significantly reduced the total number of first-instar larvae. Moreover, only $\approx 10 \%$ of these larvae achieved the adult stage when compared with control groups. These data indicate that azadirachtin is able to affect the longterm development of the few insects derived from treated females.

It is still important to conduct more conclusive studies concerning breeding of these vectors and the field application of our results. For example, female sand flies disassociate the location of biting and oviposition according to the available attractive or repellant subtrates in the environment. Moreover, it is also necessary to assess the possible impacts of azadirachtin on nontarget organisms (i.e., spiders, praying mantis, or ground beetles), by the use of sugar-baited or soil sprayed strategies (Müller and Schlein 2006; Müller et al. 2008, 2010a,b; Qualls et al. 2014) .

The study presented here, together with data from Andrade-Coelho et al. (2006, 2009), provide strong evidence that azadirachtin A can be a helpful tool for studying the neuroendocrine system and physiology of phlebotomines, thus helping identify important targets for sand fly control.

\section{Acknowledgments}

We are grateful to Fernando T. Silveira, Iorlando R. Barata, $\mathrm{M}^{\mathrm{a}}$ Sueli B. Pinheiro, and all technicians of the Evandro Chagas Institute (Leishmaniases Laboratory, Rio de Janeiro, Brazil) for supporting research and supplying Lu. longipalpis. This investigation was supported by Fundação de Amparo a Pesquisa do Rio de Janeiro (FAPERJ) and Fundação Oswaldo Cruz (FIOCRUZ).

\section{References Cited}

Alves, A. W. 2009. Leishmaniasis: current situation in Brazil. Bepa 6: 25-29.

Andrade-Coelho, C. A., N. A. Souza, D. Feder, C. E. Silva, E. G. Souza, P. Azambuja, M. S. Gonzalez, and E. F. Rangel. 2006. Effects of Azadirachtin on the Development and Mortality of Lutzomyia longipalpis Larvae
(Lutz \& Neiva, 1912) (Diptera: Psychodidae: Phlebotominae). J. Med. Entomol. 43: 262-266.

Andrade-Coelho, C. A., N. A. Souza, V. C. Silva, M. S. Gonzalez, and E. F. Rangel. 2009. Effect of fruits and leaves of Meliaceae plants (Azadirachta indica and Melia azedarach) on the development of Lutzomyia longipalpis larvae (Lutz \& Neiva, 1912) (Diptera: Psychodidae: Phlebotominae). J. Med. Entomol. 46: 1125-1130.

Armitage, P., and G. Berry. 1994. Analysis of variance, pp. 233-256. In Statistical methods in medical research, 3rd ed. Blackwell, Oxford, United Kingdom.

Ayres, M.A.M. Jr., D. L. Ayres, and A. M. Santos. 2005. Bioestat 4.0 Aplicacões Estatísticas nas Áreas das Ciências Biológicas e Médicas. Imprensa Oficial do Estado do Pará, Brasil.

Barraud, P. J. 1929. A simple method for carriage of living mosquitos over long distances in the tropics. Indian J. Med. Res. 17: 281-285.

Cunha, A. M., and E. Chagas. 1937. Nova espécie de protozoário do gênero Leishmania patogênico para o homem. Leishmania chagasi n.sp. Nota prévia Hospital (Rio de Janeiro) 11: 3-9.

Feder, D., D. Valle, R. Rembold, and E. S Garcia. 1988. Azadirachtin-induced sterilization in mature females of Rhodnius prolixus. Z. Naturforsch 43c: 908-913.

Garcia, E. S., N. Luz, P. Azambuja, and H. Rembold. 1990. Azadirachtin depresses release of prothoracicotropic hormone in Rhodnius prolixus larvae: Evidence from head transplantation. J. Insect. Physiol. 36: 679-682.

Guerin, P. J., P. Olliaro, S. Sundar, M. Boelaert, S. L. Croft, P. Desjeux. 2002. Visceral leishmaniasis: current status of control, diagnosis and treatment and a proposed research and development agenda. Lancet Infect Dis. 2: $494-501$.

Koul, O., M. B. Isman, and C. M. Ketkar. 1990. Properties and uses of neem, Azadirachta indica. Can. J. Bot. 68: 1-11.

Lainson, R., and E. F. Rangel. 2003. Flebotomíneos do Brasil, pp. 311-336. Ecologia das leishmanioses, Editora FIOCRUZ, São Paulo, Brasil.

Mahmood, F., D. A. Carlson, D. Borovsky. 1992. Biosynthesis and Metabolismo of Juvenile Hormone III from Methyl Farnesoate by Exposed Corpora Allata of Lutzomyia anthophora. J. Med. Entomol. 29: 548-555.

Marcondes, C. B. 2007. Taxonomic changes: disprove or accept them. Trends Parasitol. 23: 302-303.

Müller, G. C., and Y. Schlein. 2006. Sugar questing mosquitoes in arid areas gather on scarce blossoms that can be used for control. Int. J. Parasitol. 36: 1077-1080.

Müller, G. C., V. D. Kravchenko, and Y. Schlein. 2008. Decline of Anopheles sergentii and Aedes caspius populations following presentation of attractive, toxic (Spinosad) sugar bait stations in an oasis. J. Am. Mosq. Control Assoc. 24: 147-149.

Müller, G. C., J. C. Beier, S. F. Traore, M. B. Toure, M. M. Traore, S. Bah, S. Doumbia, Y. Schlein. 2010a. Successful field trial of attractive toxic sugar bait (ATSB) plantspraying methods against malaria vectors in the Anopheles gambiae complex in Mali, West Africa. Malar. J. 9: 210.

Müller, G. C., A. Junnila, and Y. Schlein. 2010b. Effective control of adult Culex pipiens byspraying an attractive toxic sugar solution in the vegetation near larval habitats. J. Med. Vet. Entomol. 47: 65-67.

Qualls, A. W., C. G. Müller, E. E. Revayc, S. A. Alland, K. L. Arhearta, J. C. Beiera, M. L. Smithe, J. M. Scotte, V. D. Kravchenkof, A. Hausmanng, et al. 2014. Evaluation of attractive toxic sugar bait (ATSB) - Barrier for control of vector and nuisance mosquitoes and its effect on non- 
target organisms in sub-tropical environments in FloridaWhitney. Acta Trop. 131: 104-110.

Rangel, E. F., N. A. Souza, E. D. Wermelinger, and A. F. Barbosa. 1985. Estabelecimento de colônia, em laboratório, de Lutzomyia intermedia (Lutz \& Neiva, 1912) (Diptera: Psychodidae: Phlebotominae). Mem. Inst. Oswaldo Cruz. 80: 219-226.

Redfern, R. E., J. D. Warthen, E. C. Uebel, Jr., and G.D.R. Mills, Jr. 1981. The antifeedant and growth-disrupting effects of azadirachtin on Spodoptera frugiperda and Oncopeltus fasciatus, pp. 129-136. In H. Schumutterer, K.R.S. Ascher, and H. Rembold (eds.), Natural pesticides from the neem tree. Proceedings of the 1st International Neem Conference, Rottach-Egern. German Agency for Technology Cooperation, Eschborn, Germany.

Rembold, H. 1984. Secondary plant products in insect control with special reference to the azadirachtins, pp. 481491. In W. Engels (ed.), Advances in invertebrate reproduction, vol. 3. Elsevier North Holland, New York, NY.
Rembold, H. 1987. The azadirachtins potent insects growth inhibitors. Mem. Inst. Oswaldo Cruz. 82: 61-66.

Rembold, H. 1989. The azadirachtins - their potential for insect control. Econ. Med. Plant. Res. 3: 903-907.

Rembold, H., and K. P. Sieber. 1981. Inhibition of oogenesis and ecdysteroid synthesis by azadirachtin in Locusta migratoria migratorioides $(\mathrm{R}+\mathrm{F})$. Z Naturforsch. 36c: $466-$ 469.

Subrahmanyam, B., and H. Rembold. 1989. Effects of azadirachtin A on neuroendocrine activity in Locusta migratoria. Cell. Tissue Res. 256: 513-517.

Ward, R. D. 1977. The colonization of Lutzomyia flaviscutellata (Diptera: Psychodidae), a vector of Leishmania mexicana amazonensis in Brazil. J. Med. Entomol. 14: 469 476.

(WHO) World Health Organization. 2013. Neglected tropical diseases. (http://www.who.ch/ctd/).

Received 16 October 2012; accepted 7 May 2014. 